\title{
Rinoserebral Mukormikozlu Bir Olgu
}

\author{
A Case Report of Rhinocerebral Mucormycosis
}

\author{
Özay AKYILDIZ
}

Acıbadem Adana Hastanesi, Enfeksiyon Hastalıkları ve Klinik Mikrobiyoloji Kliniği, Adana, Türkiye

Geliş Tarihi: 05.09.2019 Kabul Tarihi: 03.12.2019 DOI: 10.17517/ksutfd.616036

Özet

Mukormikoz nadir görülen ve sıklıkla yüksek mortalite ile seyreden invaziv fırsatçı bir mantar enfeksiyonudur. Altta yatan hastalı̆̆ın düzeltilmesi, agresif cerrahi debridman ve sistemik amfoterisin B tedavinin esasını oluşturur. Etken, doğada yaygın olarak bulunmasına rağmen genellikle bağışıklık sistemi baskılanan veya kontrolsüz diyabeti olan bireylerde hastalık oluşturmaktadır. İnvaziv fungal enfeksiyon insidansı hematopoetik kök hücre nakli (HKHT) hastalarında yüksek oranda görülürken, yalnızca kemoterapi alan hastalarda görülme sıklığı daha düşüktür. Literatürde yalnızca kemoterapi alan multipl miyelom hastalarında mukormikoz geliştiğine dair olgu bildirimi çok az sayıdadır. Bu yazıda multiplmiyelomlu bir hastada gelişen rinoserebral mukormikoz olgusunun sunulması amaçlanmıştır. Son dönemde immünsüprese hasta sayısındaki artış nedeniyle mukormikoz görülme sıklığı artmıştır. Sonuç olarak, Bu olgu sunumunda, diyabetik olmayan ve HKHT yapılmayan multipl miyelomlu hastalarda da mukormikoz gelişebileceğine ve immünsüpresif olgularda invaziv fungal enfeksiyonların tedavisinin büyük zorluk gösterdiğine vurgu yapılmışır.

Anahtar kelimeler: Mukormikoz, multipl miyelom, invaziv fungal enfeksiyon

\footnotetext{
Abstract

Mucormycosis, an invasive and opportunistic fungal infectious disease, is a rare disease with high mortality rate. The main treatment options in mucormycosis are, treating the underlying diesase, aggressive surgical debridement and systemic amphotericin B. Although the causative agent of mucormycosis is widespread in natural environment, it usually is being observed in patients with immunsuppression or uncontrolled diabetes. Invasive fungal infection is frequently seen in patients with the history of hematopoetic stem cell transplantation (HSCT). This rate is lower with patients who are receiving chemotheraphy. In literature, there are very few mucormycosis cases in multiple myeloma patients, who are receiving chemotheraphy only. In this paper, we aimed to present a case with rhinocerebral mucormycosis in a patient with multiple myeloma. Recently, an increase in the incidence of mucormycosis is being observed related to the rise in the immunosuppressive patient numbers.

In conclusion, This presentation emphasizes the possibility of mucormycosis infection in multiple myeloma patients without any history of diabetes or hematopoietic stem cell transplantation and the difficulty of the treatment of invasive fungal infections with immunsupresive patients.
}

Key words: Mucormycosis, multiple myeloma, invasive fungal infection

Yazışma adresi: Özay AKYILDIZ Acıbadem Adana Hastanesi, Enfeksiyon Hastalıkları ve Klinik Mikrobiyoloji Kliniği, Adana, Türkiye

Tel: +90-5056167107 Mail: osaymeclis@yahoo.com

ORCID No: 0000-0003-4566-4874 


\section{GİRIŞ}

Mukormikoz nadir görülen, sıklıkla hızlı ilerleyen, erken tanısı ve tedavisi yapılmazsa ölümle sonuçlanabilen invaziv firsatçı bir mantar enfeksiyonudur. Genellikle bağışıklık sistemi baskılanan veya kontrolsüz diyabeti olan hastalarda görülür. Sorumlu etkenler, Zygomycetes sinıfinın Mucorales takımından Rhizopus, rhizomucor, Mucor ve Absidia cinslerindeki mantarlardır. Mukormikoz klinikte rinoserebral, pulmoner, merkezi sinir sistemi (MSS), gastrointestinal ya da subkütan yerleşimli, nadiren de dissemine olarak ortaya çıkar. Mukormikozun en yaygın formu rinoserebral mukormikozdur. Rinoserebral mukormikozda paranazal sinüzit, baş ve yüz ağrısı, ateş yüksekliği, burun akıntısı, nazal ülserasyon, görme problemleri görülür. Paranazal sinüslerden intrakraniyal bölgeye yayılımı kafa tabanı bölgesinden meydana gelir. Sinüs içerisinde bulunan fungal elemanlar kemik erozyonuna yol açarak orbitaya, vasküler yollarla kavernöz sinüse ve intrakraniyal bölgeye yayılabilir (1). Tanı, dokuda septumsuz hiflerin görülmesiyle konulur ve kültürle tür ayrımı yapılır. Altta yatan hastalığın düzeltilmesi, agresif cerrahi debridman ve sistemik amfoterisin B tedavinin esasını oluşturur. Bu yazıda multipl miyelom (MM) nedeniyle kemoterapi, radyoterapi öyküsü olan hastada gelişen rinoserebral mukormikoz olgusunun sunulması amaçlanmıştır.

\section{OLGU SUNUMU}

Yetmiş beş yaşında kadın hasta on günlük süreçte gittikçe artan sol göz arkasına lokalize ağrı, sol gözde şişlik, son üç gündür gelişen çift görme ve uykuya meyil şikâyeti ile acil servise başvurdu. Özgeçmişinde kronik böbrek hastalığı, hipertansiyon, koroner arter hastalığı vardı. Soygeçmişinde özellik yoktu. İki yıldır MM nedeniyle kemoterapi (KT), radyoterapi (RT) alma öyküsü vardı. Dokuz kür bortezomib+siklofosfamid+dexametazon KT'si almış, acile başvurusundan bir ay önce de iki kür vinkristin+adriamisin+doksorubisin KT’si alma öyküsü olan hasta onkoloji servisine yatırıldı. Hastanın vital bulguları stabildi. Fizik muayenede genel durumu kötü, bilinç konfüze, uykuya meyilli, sol göz ödemli ve sol göz hareketleri tüm yönlere kısıtlı, akciğer (AC) bazallerde solunum sesleri azalmış idi. Laboratuvar tetkiklerinde nötropeni (lökosit $1000 / \mathrm{mm}^{3}$, nötrofil $\left.300 / \mathrm{mm}^{3}\right)$, CRP yüksekliği $(18,5$ $\mathrm{mg} / \mathrm{dl}$ ) ve tam idrar tetkikinde piyüri vardı. AC grafisinde her iki AC tüm zonlarda konsolide ve retiküler görünümde infiltrasyonlar izlendi. Hastaya piperasilin tazobaktam 3x4,5 gr IV tedavi başlandi. İdrar kültüründe Klebsiella pneumoniae, balgam kültüründe Stenotrophomonas maltophilia üremesi oldu. Kan kültüründe üreme olmadı. Tedaviye Trimetoprim-Sulfametaksazol (TMP/SMX) 3X2 amp. IV tedavi eklendi. Göz hastalıklarının değerlendirmesinde, sağ göz ve çevresi yumuşak doku doğal izlenirken sol göz kapaklarında ödem ve lenfanjiektazi izlendi. Diğer göz yapıları doğal, göz içi basıncı normal sınırlarda ve fundus değerlendirmesi doğal saptandı. Hastanın kooperasyonu zayıf olduğu için görme keskinliği değerlendirilemedi, ancak çift gördüğünü ifade ediyordu. Glob hareketleri lateral dışında tüm yönlere kısıtlı idi. Hastanın beyin ve orbita MR’ı çekilmesi önerildi. Orbita MR'ı bilateral kavernöz sinüslerde hafif kontrast tutulumu ve bilateral süperior oftalmik venlerde solda daha belirgin hafif dilatasyon, solda retrobulber yağlı dokuda kirlenme bulgusu ile birlikte pansinüzit bulguları, beyin MR’ı kortikal atrofik değişiklikler, bilateral kavernöz sinüslerde hafif kontrast tutulumu, pansinüzit bulguları olarak raporlandı. Hastanın klinik ve görüntülemelerinden mukormikoz düşünülerek yatışının dördüncü gününde lipozomal amfoterisin B 5mg/kg/gün tedavisi başlandı. Destek ve antimikrobiyal tedavilerine devam edildi. KBB muayenesinde nazal kavitede krutlar, solda septumda nekrotik alan görüldü ve her iki nazal kaviteden biyopsi alınd. Biyopsi sonucu mukormikoz ile uyumlu olarak raporland1 (Resim 1). Paranazal sinüs BT'si sfenoid ve bilateral maksiller sinüzit, sol süperior orbital fissür düzeyinde asimetrik yumuşak doku (mukor?) olarak raporlandı (Resim 2). Hastaya antifungal tedavinin beşinci gününde sinonazalmukormikoz nedenli endoskopik sinüs cerrahisi yapıldı. Geniş debridman, antero-posterior etmoidektomi ve sfenoidektomi yapıldı. Perop kültürlerde üreme olmadı. Histopatolojik incelemesi mukormikozisle uyumlu saptand. Takipte hastanın nötropenisi uygun tedavilere rağmen düzelmedi ve bilinci progresif bozuldu. Antifungal tedavi verilip cerrahi olarak müdahale edilmesine rağmen hasta tedavisinin 40.gününde solunum arresti gelişmesi üzerine eksitus oldu.

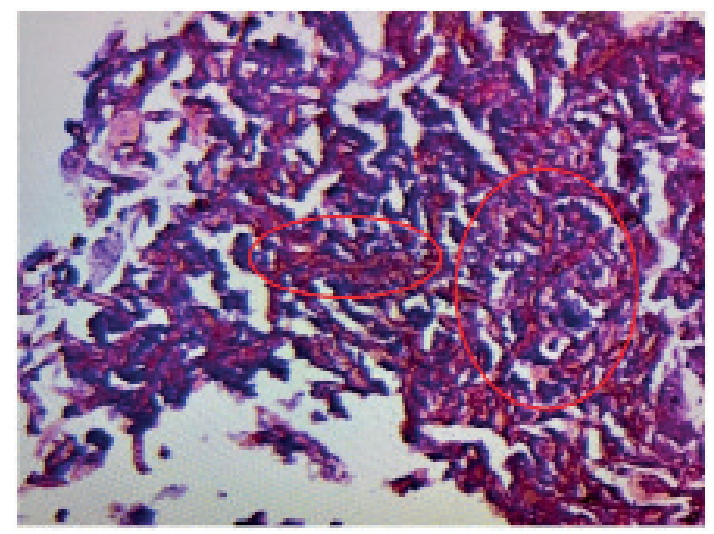

Resim1. Biyopsi örneğinde hematoksilen-eozin ile boyanmış septum göstermeyen ve dik açıyla dallanan hifler.

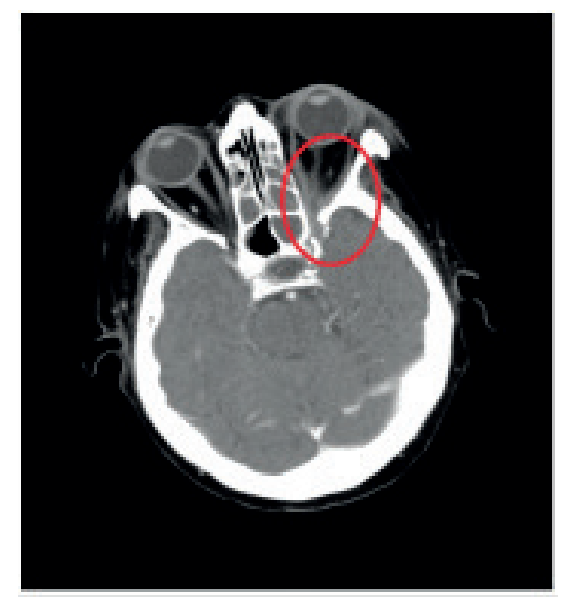

Resim 2. Paranazal sinüs BT'sisfenoid ve bilateralmaksiller sinüzit, sol süperiororbitalfissür düzeyinde asimetrik yumuşak doku (mukor?) 


\section{TARTIŞMA}

Rinoserebral mukormikoz, diyabetik hastalarda, hematolojik malignitelerde ve immünosüpresyona bağlı nötropeniklerde sık görülen, hızlı ilerleyen ve ölümcül bir enfeksiyondur (2). İnvaziv fungal enfeksiyon insidansı HKHT hastalarında yüksek oranda görülürken, yalnızca kemoterapi alan hastalarda görülme sıklığı daha düşüktür (3). Bizim olgumuz da MM nedeniyle yalnızca KT, RT almış olup buna bağlı immünosüpresyon gelişmişti. Serilere bakıldığında mukormikoz hematolojik maligniteler içinde en sık akut lösemilerde görülmektedir. Pagano ve arkadaşlarının serisinde bu oran \%78 olarak bildirilmiștir (4). Literatürde yalnızca KT alan MM hastalarında mukormikoz geliştiğine dair çok az olgu bildirimi bulunmaktadır $(5,6,7)$.

Mukormikoz çoğunlukla paranazal sinüslerden orbital veya kraniyal alana yayılan agresif bir enfeksiyon olduğundan radyolojik görüntüleme tanıda çok önemlidir. Bilgisayarlı tomografide sinüsleri dolduran değişik dansitede izlenebilen görünüm oluşturmaktadır. Sinüslerin komşuluğundaki yapılara yayılım göstermesi, bakteriyel sinüzitten ayırımda oldukça yardımcı bir bulgudur. Manyetik rezonans görüntülerde, sinüs içerisinde T1 ve T2 ağırlıklı görüntülerde hiflerin oldukça düşük sinyal yapısı göstermesi nedeniyle hipointens sinyal yapısı oluşturur. Kontrastlı görüntülerde mukor odağı belirgin kontrast tutulumu göstermezken, çevresi boyunca yaygın infiltrasyona bağlı belirgin kontrast tutulumu izlenir. Kavernöz sinüslere invazyon oluşturduğunda kraniyal sinir ve internalkarotid arterleri infiltre ederek mortalitesi yüksek komplikasyonlara yol açabilir. Olgumuzda da beyin MR'ında kavernöz sinüslerde kontrast tutulumu mevcuttu ve kliniği oldukça mortal seyretti.

Mukormikozda tedavinin başarısı, tanının erken konulabilmesi ve tedavinin erken başlanmasıyla yakından ilişkilidir. Hematolojik maligniteli 70 olgunun analizinde tedavinin düzenlenmesindeki altı günlük gecikmenin dört hafta sonundaki mortaliteyi iki kat artırdığı raporlanmıştır (8). Tedavide birinci seçenek amfoterisin B'dir. Amfoterisin B'nin lipozomal formları daha düşük yan etkileri olması nedeni ile tercih edilir. Medikal tedavi yanında enfeksiyonun yerleşim bölgesine göre cerrahinin eşzamanlı ya da yakın zamanlı uygulanması tedavinin başarısını artırmaktadır. Etkili tedavi açısından tüm nekrotik dokular debride edilmeli ve debridman sonrası antifungal solüsyonlarla operasyon bölgesi y1kanmalıdır $(9,10)$. Bizim olgumuzda da operasyon sırasında antifungal solüsyonlarla yıkama yapılmış, geniş cerrahi debridmanın yanı sira etmoidektomi ve sfenoidektomi de yapılmıştır. Sistemik tedavi olarak amfoterisin B uygulanmıştır.

Mukormikoz olgularında, infraorbital alanda ödem ve siyah renk değişikliği, burun vestibülü ile nazal kavite içinde siyah kurutlanmalar ve nekrotik görünüm patognomonik olsa da kesin tanı histolojik olarak çok sayıda geniş septasız fungal hifaların görülmesi ile ve fungusun primer kültürünün yapılması ile konulur $(11,12)$. Olgumuzda histolojik olarak çok sayıda geniş septasız fungal hifalar görüldü ancak kültürde üreme saptanmadı. Klinik bulgularla birlikte mukormikoz tanısı konuldu.

Hastaların çoğunda yapılan cerrahi ve antifungal tedaviye karşın prognoz kötüdür $(13,14)$. Rinoserebral mukormikozda prognoz ile ilgili Roden ve ark. (15) nın yaptığ 1 1885'den beri bidirilen 929 olguyu değerlendirdikleri çalışmada rinoserebral yerleşimde \%62 mortalite saptamışlardır. Olgumuz tanı anında vakit kaybetmeksizin geniş cerrahi debridman uygulanmasına ve eş zamanlı olarak antifungal tedaviye başlanmasına rağmen kaybedildi.

Mukormikoz hızlı tanı ve tedavi edilmezse fatal seyrettiği için, multidisipliner yaklaşım hastanın yaşam şansını arttırmak açısından önem arz eder. Mukormikoz olgularında erken tanı, altta yatan olumsuz koşulların düzeltilmesi, gerektiğinde enfekte dokunun cerrahi debridmanı ve uygun antifungal tedavinin başlanması büyük önem taşımaktadır. Olgumuz etkin antifungal tedavi ve geniş cerrahi debridmana rağmen kaybedilmiştir. İmmünsüpresif olgularda invaziv fungal enfeksiyonların tedavisinin büyük zorluk gösterdiği, olgumuzda olduğu gibi diyabetik olmayan, allojenik veya otolog HKHT yapılmayan MM hastalarında da mukormikoz gelişebileceği akılda tutulmalıdır.

\section{KAYNAKLAR}

1. Takahashi H, Hinohira Y, Hato N, Wakisaka H, Hyodo J, Ugumori $\mathrm{T}$ et al. Clinical features and outcomes of four patients with invasive fungal sinusitis. Auris Nasus Larynx 2011;38: 289294.

2. Nazik S, Mercan ND, Sarıca S, Kazancı Ü, Șahin AR, Ateș S. HurryUp! If not treated, Mucormycosis is lethal. J Clin Anal Med 2019; 10(3): 411-3.

3. Kurosawa M, Yonezumi M, Hashino S, Tanaka J, Nishio M, Kaneda $M$, et al. Epidemiology and treatment outcome of invasive fungal infections in patients with hematological malignancies. Int J Hematol 2012 Dec;96(6): 748-57.

4. Pagano L, Ricci P, Tonso A, Nosari A, CudilloL, Montillo M, et al. Mucormycosis in patients with haematological malignancies: a retrospective clinical study of 37 cases Br J Haemotol 1997;99: 331-336.

5. Gattenlöhner S,Unzicker C,Wörner S,Stuhler G,Einsele H,Müller-Hermelink HK. Disseminated mucormycosis of an immunocompromised multiple myeloma patient: impact of biopsy of extramedullary tumours in refractory multiple myeloma. Ann Hematol 2009; 88: 385-387.

6. Pastor E, Real E, Grau E. Splenic mucormycosis. Haematologica 1999; 84: 375 .

7. Virmani R, Connor DH, McAllister HA. Cardiac mucormycosis. A report of five patients and review of 14 previously reported cases. Am J Clin Pathol 1982; 78(1): 42-7.

8. Chamilos G, Lewis RE, Kontoyiannis DP. Delaying amphotericin B-based frontline therapy significantly increases mortality among patients with hematologic malignancy who have zygomycosis. Clin Infect Dis 2008;47(4): 503-9.

9. Maschmayer G. The changing epidemiology of invasive fungal infections: new threats. Int J Antimicrobial Agents 2006;27(Suppl 1): 3-6. 
10. Michallet M, Ito JI. Approaches to the management of invasive fungal infections in hematologic malignancy and hematopoietic cell transplantation. J ClinOncol 2009;27: 3398-3409.

11. Kara M, Erdoğan H, Toroslu T, Akçalı A, Okun MT, Reşorlu M, Dereköy FS. Rino-orbito-serebral mukormikozis: Literatür eşliğinde iki olgu sunumu. Kulak Burun Boğaz IhtisDerg. 2015;295-301.

12. Sağıt M, Yaşar M, Hıra İ, Polat H, Karaman H. Mucormycosis causing paralysis of abducens and facial nerves. ENTcase 2015;1: 30-35.

13. Dubey A, Patwardhan RV, Sampth S, Santosh V, Kolluri S, Nanda A. Intracranial fungal granuloma: analysis of 40 patients and review of the literature. Surg Neurol 2005;63(3): 254-60.

14. İslam A, Oğuz H, Demirci M, Arslan N, Şafak MA, Felek S. Rinoserebral mukormikozis: Fasial ve palatal nekroz olgu sunumu. KBB ve BBC Dergisi 2006;14(1-3): 67-71.

15. Roden M, Zaoutis TE, Buchanan WL, Knudsen TA, Sarkisova TA, Schaufele RL et al. Epidemiology and outcome of zygomycosis: a review of 929 reported cases. Clinical Infectious Diseases 2005;5: 634-653. 